\title{
Çalışanların Öz Liderlik Becerileri ve Yenilikçilik Davranışı: Gelişim Kültürünün Aracı Etkisi Adıyaman Organize Sanayii Bölgesindeki İşletmelerde Araştırma ${ }^{1}$
}

\author{
Tuba BÜYÜKBEŞE \\ Doç. Dr., Hasan Kalyoncu Üniversitesi, \\ İktisadi ve İdari Bilimler Fakültesi, İşletme Bölümü \\ tubabuyukbese@hku.edu.tr \\ Orcid ID: https://orcid.org/0000-0003-4174-9870
}

\author{
Erkan SARSICI \\ Öğr. Gör. Dr., Adıyaman Üniversitesi, Besni Meslek Yüksekokulu \\ sarsicierkan@yahoo.com \\ Orcid ID: https://orcid.org/0000-0002-8719-9205
}

\author{
Burcu ERSAHAN \\ Doç. Dr., Kahramanmaraş Sütçü İmam Üniversitesi, \\ İktisadi ve İdari Bilimler Fakültesi, Uluslararası Ticaret ve Lojistik Bölümü \\ bersahan@ksu.edu.tr \\ Orcid ID: https://orcid.org/0000-0003-2546-0567
}

\section{Öz}

Günümüz koşullarında firmaların varlıklarını devam ettirilebilmeleri için rekabet yeteneğine sahip olmaları gerekmektedir. Örgütlerin rekabet edebilmeleri için çalışanlarının açık fikirli olması ve öz liderlik yeteneklerinin desteklenmesi gerekmektedir. Bu durum şirketlerin rekabet gücünü arttıracak ve avantaj sağlayacak önemli bir olgudur. Bu kapsamda çalışanların öz liderlik becerileri ve yenilikçi davranışlarında gelişim kültürünün aracılık rolü üzerine tespitler yapmak bu çalışmanın temel amacını oluşturmaktadır. Adıyaman organize sanayi bölgesinde yapılan bu çalışma ile 400 çalışana anket dağıtılmıştır. Elde edilen bulgular sonucunda, öz liderlik becerileri yenilikçi davranışlarını olumlu yönde etkilediği ve bu etkiye gelişim kültürünün aracı etkisi olduğu belirlenmiştir.

Anahtar Kelimeler: Öz Liderlik, Yenilikçi Davranış, Gelişim Kültürü.

\footnotetext{
${ }^{1}$ Makale Geliş/Kabul Tarihi: 30.05.2018 / 10.06.2019

Künye Bilgisi: Büyükbeşe, T., Sarsıcı, E. ve Erşahan, B. (2019). Çalışanların Öz Liderlik Becerileri ve Yenilikçilik Davranışı: Gelişsim Kültürünün Aracı Etkisi Adlyaman Organize Sanayii Bölgesindeki Işsletmelerde Araşttrma. Kahramanmaraş Sütçü İmam Üniversitesi Sosyal Bilimler Dergisi, 16 (2), 527-554. DOI: 10.33437/ksusbd.428510
} 


\title{
Employee Self Leadership Skills and Innovation Behavior: Development Cultural Tool Impact Research in Businesses in Adıyaman Organize Industry Region
}

\begin{abstract}
In today's conditions, companies need to have competitiveness in order to be able to maintain their assets. Self leadership skills and open mindness should be supported in organization to compete with others. This is an important opportunity that will increase the competitive power of companies and provide an advantage. In this context, the main purpose of this study is to make determinations on the role of development culture in the self-leadership skills and innovative behaviors of employees. This study was conducted in the Adiyaman organized industrial region, questionnaires were distrubuted to 400 employees. As a result of the findings, it was determined that self-leadership skills influenced innovative behaviors positively and this effect was mediated by the developmental culture.
\end{abstract}

Keywords: Self-Leadership, Innovative Behavior, Culture of Development.

\section{GíRİş}

Öz liderlik yeteneğine ve yenilikçi davranışlara sahip çalışanlar üzerinde gelişim kültürünün etkisi önemli girdi değişkenlerdendir. Yenilikçilik, yeni bir fikir, bilgi veya düşünce ile başlar, düşünürün gelişim kültürünün desteği ve öz liderlik becerisi ile yenilikçi fikir aktif bir eyleme dönüşerek inovasyonel bir ürün olarak hayat bulur. Örgütlerin; Pazara hakimiyet alanlarını büyütmeleri, kazançlarını ve rekabet güçlerini arttırabilmeleri için sürekli olarak ürünlerini, bilgilerini ve hizmetlerini güncellemeleri ve yenilemeleri gerekmektedir. $\mathrm{Bu}$ faaliyetler sadece üst yönetim tarafından değil çalı̧̧anlar tarafından da benimsenip kabullenildiği takdirde başarıya ulaşabilir. Çünkü; teknolojideki hızlı gelişmeler, kaynaklara ulaşmanın zorluğu, maliyetlerin artması, ekonomik ve siyasi krizler, globalleşme ve artan rekabet baskısı üst yönetimin aldığı kararları belirli yetkinliklere sahip olmayan örgüt çalışanlarına uygulamaları oldukça zordur. Gelişmiş teknoloji hizmetlerinin kullanıldığı, alanında yetişmiş ve deneyimli personel istihdamına ihtiyaç duyan, rekabet gücü ve başarısının sürekliliği için çalışanların, yenilikçi ve geliştirici sorumluluklar alması beklenmektedir.

Yöneticiler zor şartların üstesinden gelebilmek ve sektörde başarılı olabilmek için diğer personelden farklı düşünen, yenilikçi faaliyetler ve yaratıcı fikirler 
üreten, proaktif, girişimci çalışanlara yetki vererek öz liderliklerini desteklemelidir (Perry vd. 1999:42). Çalışanlar kendilerine verilen yetki ile birlikte ürettikleri yenilikçi davranışların, iş alanlarında ve kendi sektörlerinde performans veya verimlilik artışı sağlayacaklarına inandıkları zaman, kendi örgütlerinde sergileyecekleri performans sonuçlarının pozitif olacağı bilinmektedir (Ostroff ve Schmitt, 1993:50).

Son y1llarda öz liderlik, yenilikçi davranış ve gelişim kültürü rekabet gücünün elde edilmesinde önemli faktörler olarak karşımıza çıkmaktadır ve her geçen gün önemi artmaktadır. Çalı̧̧anların öz liderlik yetenekleri ve yenilikçi davranışlarının arttırılması için bir örgüt kültür türü olan gelişim kültürü ruhuna sahip olmaları gerekmektedir.

\section{LITERATÜR}

\section{1. Öz Liderlik}

Klasik yaklaşıma göre bir örgüt içerisinde, çalışanların kendi kendilerini yönetebilme, yönlendirebilme ve kontrol edebilme yeteneklerine "kendi kendine yönetim” adı verilmektedir. "Öz liderlik kavramı"nı ilk olarak Manz "kişilerin; kişisel ve kurumsal başarıyı yakalayabilmek için, kendi performanslarını arttıracak şekilde kendilerini yönlendirme süreci” olarak açıklamıştır (Manz, 1986:585). Örgütsel davranış hakkında son otuz yıl içinde yapılan çalışmalarda öz liderlik konusuna, dikkat çekecek derecede önem verildiği ve araştırmacıların da büyük ölçüde ilgisini çektiği izlenmektedir (Stewart vd. 2011:195). Öz liderlik ile ilgili yapılan çalışma ve uygulamaların son yıllarda büyük bir artış göstermesinin temel nedeni; bireysel ve örgütsel performansın arttırılmasında büyük ölçüde etkili olduğunun düşünülmesidir (Neck vd. 2006:289).

İş yaşamında dikkat edilmesi gereken rekabet ve başarı zorlukları ile beraber, istenen bilgilere çok hızlı bir şekilde erişim sağlanması, iletişim imkanlarındaki yükseliş, şeffaflaşma ve bunlarla beraber sağlanan işbirliği, paylaşma, ekip çalışması gibi faaliyetler örgüt içindeki en küçük birim ve etkisiz bireylerin hem daha etkin olmalarını sağlamış, hem de güçlerini eskisine göre daha fazla arttırmıştır. Artık vatandaşlar-devletlerin, tüketiciler-işletmelerin ve çalışanlarişverenlerin karşısında daha etkin bir konuma gelerek söz sahibi olmuşlardır. Bireylerin avantaj1 olarak ortaya çıkan bu faaliyet ve eylemler kurum yöneticilerinin klasik anlayışla, güce dayalı yönetim yaklaşımlarını kullanarak liderlik etmelerini zorlaştırmaktadır. Yukarıda bahsedilen teknolojik ve bilgiye dayalı gelişmeler liderlerin, liderlik yapma yaklaşımlarının yeniden gözden geçirilerek incelenmesini gerektirmektedir (Kayral, 2015:144). Kâr elde etmek amacıyla veya hizmet üretmek amacıyla kurulan örgütlerin belirlemiş oldukları hedeflere ulaşabilmeleri için mevcut liderlerin yetkilerini yenilikçi ve gelişime 
açık çalışanları ile paylaşmasının katkısı yadsınamayacak derecede fazla olacaktır.

Örgüt içinde yeniliği ve değişimi uygulamak isteyen liderler, yenilikçiliği ve gelişimi teşvik ederek, çalışanların başarma güdülerini harekete geçirir. Dolayısıyla çalışanın mevcut potansiyelinden daha fazla performans ve verimlilik sağlamaları beklenmektedir. Hem örgüt performansının hem de kişisel performansın yüksek bir başarı sağlayabilmesi için çalışanların; değişim, gelişim ve yeniliklere açık olarak kendi kendilerini yönetebilmeleri gerekmektedir. İşletmelerin yoğun rekabetin yaşandığı sektörlerde başarılı olmaları özliderlik becerilerine sahip çalışanlarla mümkündür.

Literatür taramasında yapılan araştırmalar sonucunda öz liderlik stratejileri 3 kategoriye ayrilmaktadır. Bu stratejiler;

i) Davranış odaklı strateji (behavior-focused strategies),

ii) Doğal ödül stratejisi (natural reward strategies),

iii) Yapıcı düşünce modeli stratejisi (constructive thought pattern strategies) olmak üzere üç başlık altında incelenmiştir (Neck, 2002; Houghton, 2006).

Davranış Odakı Strateji: Bireyin kendi kendisini gözlemleyerek hedeflerini belirtmesi, kendisine başarıdan dolayı ödül vermesi veya başarısızlıktan dolayı ceza vermesi, kendisine hatırlatıcı notlar alarak destek sağlayacak şekilde belirlediği stratejiler ile, kendisinin farkındalığını artırarak, davranışlarını yönetmesine yardımcı olmaya odaklıdır (Houghton 2006; Neck 2004; Anderson et al. 1997).

Doğal Ödül Stratejisi: Bu stratejinin uygulanmasının temel amacı; bireyin, görev faaliyetlerini yaptığı zamanlarda iç aleminde motivasyonunu artırmasıdır (Manz, Neck, 2004). Doğal ödül stratejisi ile davranış odaklı stratejiler arasında fark bulunmaktadır. Davranış odaklı stratejide ifade edilen kendini ödüllendirme ile bu bölümdeki doğal ödül arasındaki temel fark; çalışanın kazanacağı ödüle, tamamlanmış bir görev veya varılan bir hedef sonunda ulaşmamasıdır. Diğer bir ifade ile iş yapılırken ve faaliyet devam ederken yani ulaşılmak istenen hedefe henüz varılmamışken, kişinin bu işi yapmaktan dolayı duyduğu memnuniyetin, yapılan aktivite süresince devam ediyor olmasıdır (Manz 1992). Bu sayede birey, yapılan işin ya da görevin kendisine zevk veren taraflarına odaklanmaktadır. Doğal olarak da ödüllendirilme koşullarını süreklilik haline getirmeye çalışmaktadır. Yaptığı işten aldığı zevk devam ettiği sürece, iş performansına sağlanan motivasyon da o derece yüksek olacaktır. 
Yapıcı Düşünce Modeli Stratejisi: Her hangi bir katkısı olmayan inanç ve ön yargıları tanımlayarak negatif etkilerini yok etmeyi, hayal etmeyi ve pozitif bir şekilde kendi kendine fikirler üretme stratejilerini içermektedir. Burada önemli olan konu, bireyin kendi zihinsel modellerini kontrol edebilmesi ve yönetebilmesidir (Burns, 1980; Ellis, 1977; Neck, 2004). Çalışanın vaktini daha değerli kullanabilmesi için, kendisine zaman kaybettirecek ve faydası olmayan düşünceler ile eylemlerden vazgeçmesi gerekmektedir. Bununla beraber kendi kendine pozitif konuşmalar yaparak daha verimli ve kaliteli fikirler üretmeli ve bunları eyleme dökerek kendi başarısını göstermelidir.

\subsection{Yenilikçi Davranış}

Yenilikçi davranış; örgüt kültürüne sahip elemanların çalışma bilince sahip bir şekilde ürün, hizmet, süreç ve prosedürlere ait yeni fikirleri kendi iş rolüne, iş birimine veya örgüt organizasyonuna uygulaması ve bunları benimsemesi olarak tanımlanabilmektedir (West ve Farr,1989:20). Buckler (1996) yenilikçiliği "işletmelerin iç ve dış çevresinde meydana gelen değişim ve gelişimlere uyum sağlayabilmesi için örgüt kültüründe değer meydana getirilmesi” olarak tanımlamaktadır (Pervaiz, 1998:30).

Yenilikçi davranış; çalışanların örgütsel faaliyetlerin amaçlarına ulaşmasını sağlayacak alternatif kanallar önermesi, yeni teknolojik araçlar keşfetmeleri, yeni çalışma metotları uygulamaları ve yeni kaynakları araştırma olarak ifade edilebilir (Yuan ve Woodman, 2010:324). Örgütlerin çevresi çok değişken bir yapıya sahiptir. Bazı zamanlarda örgüt elemanları tarafindan uygulamaya konulan faaliyetler, hızlı bir aktiviteye veya değişime cevap veremeyebilir. $\mathrm{Bu}$ sebeplerden dolayı çalışanların yeni metot, prosedür ve yaklaşımlar uygulaması, desteklemesi ve geliştirmesi gerekmektedir (Shih ve Susanto, 2011:113). Bir süreç olarak yenilikçi davranış; ilk önce fikir üretimi ile başlar daha sonra uygulamaya geçer. İşletmelerin yenilikçi davranış kapasitelerini arttırması ve geliştirmesi için yenilikçi düşüncelerin açığa çıkmalarını teşvik ederek desteklemesi gerekmektedir.

Tablo 1. Çalışanların Yenilikçi Davranış Fikirlerini Cesaretlendirecek İlkeler

1. Yapılan işle ilgili olarak düşünülen varsayımları sorgularken insanları cesaretlendirmek,

2. Problemlere bakış açılarını farklı yönlere çevirmek ve farklı açılardan bakmak için insanları cesaretlendirmek, 
3. Yenilikçi fikirleri geliştirmeye zaman harcamak ve insanları bu konuda cesaretlendirmek

4. Üretilen yenilikçi fikirleri teşvik etmek, kabul etmek ve ödüller vererek devamını sağlamak.

Kaynak: G. Yukl, ve R. Lepsinger, Flexible Leadership: Creating Value by Balancing Multiple Challenges and Choices, 2004, s.116'dan uyarlanmıştır.

Kurum çalışanlarını yenilikçi davranışa sahip olmaya sevk eden sebepler arasında; örgüt içinde oluşan değişimlerin çalışanlara olan etkisi (Ör. Küçülme stratejisi uygulayan şirketlerin çalışanları, mevcut işlerini kaybetmemek için örgüt içerisindeki pozisyonlarını sağlamlaştırmak arzusu içindedirler), örgüt içinde daha fazla bağımsızlık elde etmek ve değişime ayak uydurabilmek için örgüt içindeki kronikleşmiş sorunlara çözümler üretmeleri gerekebilir (Basım vd., 2008:123). Rekabet avantajını firsata dönüştürüp, başarı rüzgarının elde edilmesi, yeniliklerin takip edilmesi ve bu yeniliklerin başarılı bir şekilde uygulamaya konulması, günümüz örgütlerinin sahip olmak istedikleri bir kültür olarak karşımıza çıkmaktadır.

Elde edilen ampirik bulgulara göre; yenilikçilik davranışı, işletmelerin rekabet avantaj1 elde etmelerinde ve örgütü bulunduğu seviyeden daha ileriye götürmelerinde pozitif etkiye sahiptir (Sorescu ve diğ., 2003:90). Deshpandé ve arkadaşları (1993) tarafından Japon firmaları arasında yapılan araştırmada, yenilikçilik ile firmanın finansal performansı arasında pozitif yönlü ilişki belirlenmiştir. Yapılan çeşitli akademik çalışmalarda yenilikçilik ile örgüt elemanlarının performansı arasında pozitif yönlü ilişki tespit edilmiştir (Selvarajan ve diğ., 2007; Han ve diğ., 1998). Yenilikçilik süreci, başarı veya başarısızlığını etkileyen temel değişken olarak değerlendirilmektedir (Fiş ve Wasti, 2009: 129, Lemon ve Sahota, 2004: 483).

\subsection{Gelişim kültürrü}

Gelişim kültürü; yenilik, uyum yeteneği, yapıc1lık ve büyümeyi esas alan (Burns ve Stalker, 1961) ve özellikle de kurum çalışanlarının gelişim ve yenilikçilikle ile ilgili motivasyonlarına olumlu katkı sağlayan bir örgüt kültürüdür (Scott vd., 2003; Lok vd., 2005). Quinn(1988)'e göre ise; Gelişim kültürü; açıklık, doğallık, cevaplanabilirlik, değişim ve uyarlanabilirlik olarak sıralanan değerleri esas almaktadır. Dış odaklı bir kültür çeşidi olarak kabul edilmektedir. Örgütlerde yer alan temel değerler; hem açık ve hem de çok çeşitli olan iletişim kanalları, çok samimi ve aynı zamanda çok da resmi olmayan kontrollerden oluşmaktadır. Böylece hiyerarşik ilişki kademelerinin tamamını kapsayan serbest bilgi aktarımını teşvik etme (Burns ve Stalker, 1961) gibi temel değer faktörlerin daha belirgin hale gelmesi sağlanmaktadır. 
Gelişim kültürü, çalışan personelin daha verimli olmasını ve motivasyonlarının yükselmesini sağlayan örgütsel bir kültürdür (Scott, vd., 2003; Lok, vd., 2005). Gelişim kültürü ve bu gibi kültürler, çalışan personelin yaptığı işle doğrudan ilgili olan değer ve tutumlarını içermekle birlikte, aynı zamanda bu değer ve tutumları güçlendirmektedir. Bu değerler ve tutumlar, kurum çalışanları tarafindan içselleştirilerek örgüt kültürüne göre gelişim kültürüne daha fazla odaklanmayı sağlamaktadır (Lok vd., 2005:500).

Gelişim kültürü değerlerinin baskın olduğu organizasyonlarda liderler; risk alabilen, idealist, girişimci ve vizyon sahibi kişilerle çalı̧̧manın daha verimli olacağı kanaatine sahiptirler. Böylece hem ek kaynakları hem de dış kaynakları elde edebilmek için şeffaflığa odaklanmakta zorlanmayacaklardır (Denison ve Spreitzer, 1991:215). Yazarların yaptıkları bu tanımlamalara göre risk alabilen, idealist, vizyonist $\mathrm{vb}$. karakterlere sahip olan kişilerin kendilerini geliştirmeleri ile birlikte örgütlerini de bir üst safhaya çıkarabilmeleri mümkündür. Aynı zamanda bu kişilerin başarılı bir girişimci olmalarının da mümkün olduğu anlaşılmaktadır.

\section{4. Öz Liderlik ve Gelişim Kültürü İliş̧kisi}

Çalışanların öz liderlik yetisine sahip olup olmadığı, sahip ise kendisine hedef belirlemesinin ve zihinsel egzersizler yapmasının etkileri farklı alanlarda araştırılmıştır. Hedef belirleme faaliyetlerinin ve zihinsel alıştırmaların nasıl yapılması gerektiği yönünde eğitim alan grup üyelerinin, bu eğitimi almayan diğer kontrol grubu üyelerine göre anlamlı derecede daha olumlu, daha yüksek kendi kendine yeterlilik davranışları gösterdiği tespit edilmiştir (Morin vd. 2000:572). Bireylerin öz liderlik ve yeterlilik algılamalarına karşı aldıkları tutumlar ve kullandıkları stratejiler ile önceden belirlenmiş olan bireysel hedeflere ulaşma düzeyleri birbirleriyle ilişkilidir. Bu bağlamda iş yerinde geliştirici, yenilikçi ve yapıcı çözümler oluşturma ile başarı düzeyleri arasında ilişkiler olması beklenmektedir (Carmeli vd. 2006:79).

Heimerdinger vd. (2008:391) tarafindan yapılan başka bir akademik çalışmada ise bireyler kendilerinin yaptıkları iş kolunda hem motive edilmeye hem de gelişim kültürlerini arttırmaya yönelik hedef belirlemektedirler. Başarısızlıktan kaçınmaya yönelik davranışlara odaklanmaları veya kendilerini başarılı ya da başarısız biçimde hayal etmelerinin de bireysel performansları ile yakından ilişki içerisinde olduğu rapor edilmektedir. Elde edilen bu veriler neticesinde çalışanlar zihinsel egzersizler yaparak ya da geleceğe yönelik hayaller kurarak belirtilen yapıcı düşünce modelini uygulama boyutu içinde yer alan başarılı performans stratejisinin, hedef belirlemeyle arasında olan ilişki ortaya konulmuştur. 
Hinsz vd. (1997:177) tarafından yapılan bir araştırmada elde edilen bulgulara göre; bireyin sergileyeceği performansta artış olması onun öz liderlik kabiliyetine etki edecektir. Böylelikle daha özgüven sahibi olacak ve hem örgütü, hem de kendisi gelişim kültürünü yansitabilecektir. Çünkü bireyin ulaşmak istediği geleceğe yönelik beklentiler, onun neyi başarmak istediği veya arzuladığı ile yaptığı hedef seçiminin bir fonksiyonu olarak değerlendirilmektedir.

Bu kapsamda öz liderlik ve gelişim kültürü stratejilerinin bir biriyle oldukça yakın ilişkili, iç içe kavramlar oldukları anlaşılmaktadır. Öz liderlik uygulamalarının bireysel ve örgütsel gelişimi artırmada çok etkili olduğu düşünülmektedir (Neck vd. 2006:289). Örgüt çalışanlarının kendi kabiliyet ve yeteneklerini geliştirmeleri ile birlikte elde edecekleri motivasyon, bu kişilerin öz lider olabilme basamaklarını bir adım daha ileriye götürecektir. Öz lider çalışarak, kendini geliştirerek elde etmiş olduğu bilgi ve tecrübeleri kendi astlarına aktararak hem kurumuna başarı sağlayacak, hem de astlarına yol göstermiş ve öncülük etmiş olacaktır. Aksi bir durumda sessiz, yönetmeye değil de yönetilmeye alışmış bir bireyin kendisini ve çevresini değiştirmeye de, geliştirmeye de gücü ve yetkisi olmayacaktır.

\subsection{Gelişim Kültürü̈ ve Yenilikçi Davranış İlişkisi}

Son yıllarda birçok farklı akademik makalede gelişim kültürü ve benzer kültürlerin çalışanların algılamalarını ve eylemlerini yönlendirecek önemli bir etken olduğu değerlendirilmiştir (Bunch, 2007:150). Bu kapsamda gelişim kültürü ile yenilikçi davranış arasında olabilecek ilişkileri araştıran çok sayıda çalışmaya rastlanmıştır. Bu çalışmalarda gelişim kültürü ile yenilikçi davranış arasında ilişki olduğuna dair bulgular tespit edilmiştir (Heracleous, 2001; Flynn ve Chatman 2001; Jaskyte, 2003; Prajogo ve McDermott 2005; Elenkov ve Manev 2009; Bates ve Khasawneh, 2005; Jaskyte, 2004).

Literatür araştırmasında doğrudan gelişim kültürü ile yenilikçi davranış arasındaki ilişkiyi araştıran çalı̧̧malar da bulunmaktadır. Örneğin Lau ve Ngo (2004) tarafından yapılan çalışmada gelişim kültürünün yenilikçi davranış üzerindeki etkisinin olumlu yönde olduğu tespit edilmiştir. Yapılan benzer bir araştırmada ise gelişim kültürünün yenilikçi davranış ile ilişkili olduğu ve gelişim kültürünün yenilikçi davranışı pozitif yönde etkilediği sonucuna varılmıştır (Akkoç vd. 2011:90). Ayrıca Weia ve arkadaşları (2011) tarafindan 223 adet Çin Halk Cumhuriyeti vatandaşlarına ait işletmelerden örneklem alındığ 1 çalışmada ise gelişim kültürünün, yeni mal ve hizmet üretimini pozitif yönde artırdığ 1 bulgusuna varılmıştır.

Örgüt kültürü gelişimi, girişimciliği ve yenilikçiliği etkileyen önemli bir faktör olarak karşımıza çıkmaktadır. Örgütlerde gelişim kültürünün de yenilikçi davranış1 destekleyeceği düşünülmektedir. 


\section{6. Öz Liderlik ve Yenilikçi Davranış İlişkisi}

Basım, vd., (2008:126) tarafindan yapılan araştırmaya göre; Öz liderliğin bireylerin iş tatminlerini, liderlik ve girişimcilik özelliklerini, performanslarını olumlu yönde etkilediği belirtilmektedir. Çalışmalar öz liderliği yüksek olan personel, öz liderliği düşük olan personel ile karşılaştırıldığında, kendi kendine yeterli olan personelin daha yüksek seviyede yenilikçi davrandığını ve risk alabildiğini göstermektedir. Özellikle günümüzde örgütlerin bu niteliklere sahip çalışanları arzuladığı göz önüne alındığında, anılan ortamlarda öz yeterliliği artııcı tedbirler alınmasının, örgütsel etkililiği ve verimliliği olumlu şekilde etkileyeceği değerlendirilmektedir.

Sahip olduğu liderlik yeteneklerine ve kabiliyetlerine güvenen, aktif bir görev esnasında risk almaktan çekinmeyen, karşılaştığı mesleki sorunları başarılı bir şekilde aşabilen, öz liderliği yüksek bireyler, yenilikçi davranışlara daha 1lımlı yaklaşmakta ve örgütsel alanda daha çok yenilikçi davranışta bulunmaktadırlar. Belirsiz ortamlarda hesaplı şekilde risk alma konusunda da, öz liderliği yüksek çalışanların, diğer çalışanlara göre daha cesur davranma eğiliminde oldukları görülmektedir. Yani, yeterliliklerine çok yüksek seviyede güvenen personelin daha yenilikçi olduğu ve karşısına çıkan krizleri daha rahat firsata çevirdiği anlaşılmaktadır.

\section{ARAŞTIRMANIN AMACI VE YÖNTEMI}

Bu çalışmanın amacı çalışanlarının öz liderlik stratejisinin yenilikçi davranışa etkisinde gelişim kültürünün aracılık rolünü belirlemektir. Amaç doğrultusunda yukarıda açıklanan literatüre dayanarak aşağıda yer alan model (Şekill) ve hipotezler kurgulanmıştır.

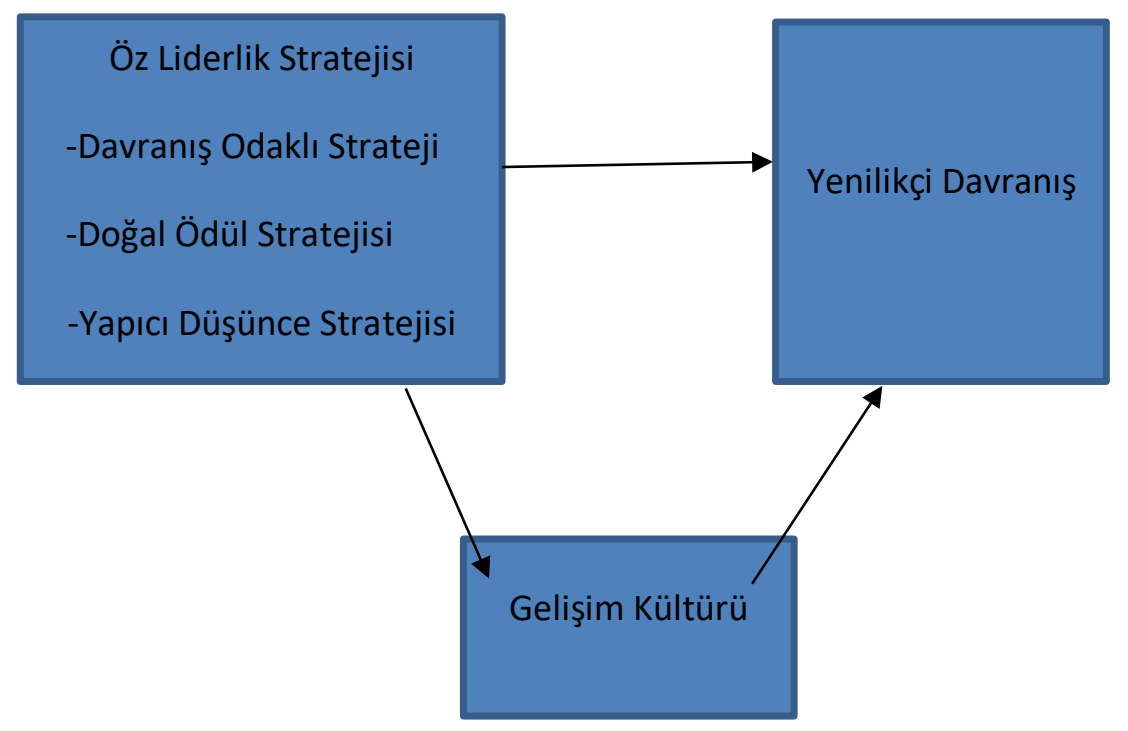


Şekil 1: Öz Liderlik Stratejisinin Yenilik Davranışına Etkisinde Gelişim Kültürünün Aracı Rolü ile İlgili Araştırma Modeli

Öz liderlik stratejisi, yenilikçi davranış ve gelişim kültürü ile ilgili hipotezler aşağıdaki gibidir.

H1: Öz liderlik stratejisi boyutları yenilikçi davranışı olumlu yönde etkilemektedir.

H1.1: Davranış odaklı strateji yenilikçi davranışı olumlu yönde etkilemektedir.

H1.2 : Doğal ödül stratejisi yenilikçi davranışı olumlu yönde etkilemektedir.

H1.3: Yapıcı düşünce stratejisi yenilikçi davranışı olumlu yönde etkilemektedir.

H2: Öz liderlik stratejisi boyutları gelişim kültürünü olumlu yönde etkilemektedir.

H2.1: Davranış odaklı strateji gelişim kültürünü olumlu yönde etkilemektedir.

H2.2 : Doğal ödül stratejisi gelişim kültürünü olumlu yönde etkilemektedir.

H2.3: Yapıc1 düşünce stratejisi gelişim kültürünü olumlu yönde etkilemektedir.

H3: Gelişim kültürü yenilikçi davranış1 olumlu yönde etkilemektedir.

H4: Öz liderlik stratejisinin yenilikçi davranışa etkisinde gelişim kültürünün Aracı rolü vardır.

H4.1: Davranış odaklı stratejinin yenilikçi davranışa etkisinde gelişim kültürünün Aracı rolü vardır.

H4.2: Doğal ödül stratejisinin yenilikçi davranışa etkisinde gelişim kültürünün Aracı rolü vardır.

H4.3: Yapıcı düşünce stratejisinin yenilikçi davranışa etkisinde gelişim kültürünün Aracı rolü vardır.

Oluşturulan hipotezleri test etmek amacıyla araştırmada; nicel araştırma yöntemi uygulanmıştır. Hazırlanan bu çalışmada, çalışanların öz liderlik stratejileri, yenilikçi davranış ve gelişim kültürlerinin değerlendirilmesi amaçlandığından veri toplama sürecinde anket tekniğinden yararlanılmıştır. Toplanan veriler SPSS istatistik paket programında değerlendirilmiştir. Öncelikle 
kişiye ve kuruma ilişkin tanımlayıcı istatistikler ortaya koyulmuştur. Daha sonra ölçeklerin geçerlilik ve güvenilirlikleri test edilmiş, sonrasında korelasyon testi ile önermeler arasındaki ilişki düzeyi ve yönü belirlenmiş ve son olarak da AMOS ile değişkenler arasındaki ilişkiler değerlendirilmiştir. Analiz sonuçları tablolar halinde sunulup raporlanmış ve elde edilen bulgular mevcut literatür ile karşılaştırılarak yönetici ve araştırmacılara önerilerde bulunulmuştur.

\subsection{Araştırmanın Örneklemi}

Araştırma evrenini Adıyaman ilinde organize sanayi bölgesinde faaliyet gösteren küçük ve orta ölçekli sanayii işletmelerinde çalışanlar oluşturmaktadır. $\mathrm{Bu}$ evrende yaklaşık 100 şirket bulunmakta ve 5000 kişi çalışmaktadır. Ana kütleden $\% 95$ güvenilirlik sınırları içerisinde $\% 5$ ' lik bir hata payı dikkate alınarak örneklem büyüklüğü 365 kişi olarak hesap edilmiştir (Sekaran, 1992: 253). Bu kapsamda kümelere göre örnekleme yöntemiyle tesadüfî olarak seçilen toplam 400 kişiye anket uygulaması yapılması planlanmıştır. Gönderilen anketlerden 390'1 geri dönmüş, 380'i analiz yapmak için uygun bulunmuştur.

\subsection{Araştırmada kullanılan ölçekler}

Öz Liderlik Stratejisi, Anderson ve Prussia (1997) tarafindan geliştirilen, doğrulayıcı çalışmaları Houghton ve Neck (2002) tarafindan gerçekleştirilen, Tabak ve diğerleri (2013) tarafindan Türkçe'ye çevrilen bir ölçek olup, literatürde farklı araştırmacılar tarafindan da (Örneğin; Kayral, 2015; Göksoy ve diğerleri,2014; Ay, 2017; Stewart ve diğerleri, 2011) kullanılmıştır. Anderson ve Prussia (1997) tarafindan geliştirilen "Öz Liderlik Stratejisi Ölçeğì" (Self Leadership Strategy Questionnaire) üç alt boyuttan oluşmaktadır. Bunlar davranış odaklı strateji (16 madde), doğal ödül stratejisi (4 madde) ve yapıcı düşünce stratejisidir (7 madde).

Davranış Odaklı Stratejisi alt boyutuna ilişkin önermeler 16 adet olup; "Başarısız olduğum zamanlarda, kendimi yetersiz bulma eğilimindeyim", "Mesleğimde ne kadar iyi olduğumu takip ederim" gibi önermeler ölçeği oluşturmaktadır.

Doğal Ödül Stratejisi alt boyutuna ilişkin önermeler 4 adet olup; "Zor bir durumla karşılaştığımda, kendi mantığıma başvurarak durumu değerlendiririm", "Bir işe başlamadan önce, kendimi o işi başarıyla tamamlamış gibi hayalimde canlandırırım", önermeleri örnek olarak verilebilir.

Yapıcı Düşünce Stratejisi alt boyutuna ilişkin önermeler 7 adet olup; "Gelecekte ulaşmak istediğim hedefleri düşünürüm", "Fikirlerim ve inançlarım hakkında düşünür ve değerlendirmeler yaparım" önermeleri örnek teşkil etmektedir. 
Yenilikçi Davranış kavramı için Scott ve Bruce tarafından geliştirilen ölçek kullanılmıştır. Scott ve Bruce (1994) tarafindan geliştirilen ve literatürde diğer araştırmacılar tarafindan da kullanılan (Örneğin; Turgut ve Begenirbaş, 2014; Akkoç, 2012) "Yenilikçi Davranış" (Innovative Behavior Questionnaire) ölçeği tek bileşenden oluşmaktadır. Yenilikçi Davranış Ölçeği'ne ilişkin önermeler 6 adet olup "Yeni teknolojiler, süreçler, teknikler araştırırım ve fikirler üretirim", "Yaratıcı fikirler üretirim", gibi önermeleri içermektedir.

Gelişim Kültürü kavramı için Quinn (1988), Quinn ve Spreitzer (1991), Wang ve Shyu (2003) tarafından geliştirilen, Tseng ve Lee (2009) tarafından kullanılan ve literatürde diğer araştırmacılar tarafindan da dikkate alınan (Örneğin; Akkoç, 2012; Akkoç ve diğerleri, 2012) ölçek kullanılmıştır. Söz konusu "Gelişim Kültürü Ölçeği”" (Culture of Development) tek bileşenden oluşmaktadır. Gelişim Kültürü Ölçeği'ne ilişkin önermeler 8 adet olup; "Çalıştı̆̆ım işletme verimlilik ve yaratıcılığa ağırlık verir", "Çalıştığım işletme AR-GE ve yeni ürüne ağırlık verir”, gibi önermeleri içermektedir.

Ankette her bir ifade için "1.Kesinlikle Katılmıyorum", "2.Katılmıyorum", "3.Kararsızım", "4.Katılıyorum" ve "5.Kesinlikle Katıllyorum" seçeneklerinden oluşan 5'li Likert ölçeğiyle değerlendirme yapılmıştır.

\section{BULGULAR}

\subsection{Demografik Değişkenler İle İlgili Tanımlayıcı İstatistikler}

Katılımcıların demografik özellikleri Tablo 2'de gösterilmiştir. Katılımcıların \%54.5'inin erkek olduğu, \%52.9'unun evli olduğu, \%38.1'inin "31-40" yaş aralığında bulunduğu, \%47.7'sinin "ön lisans" mezunu olduğu ve \%71.5'inin çalışma süresinin "1-5 yıl” arası olduğu gözlemlenmiştir. Firma personel sayısının ise en çok \%36.7 ile 10-49 arasında olduğu belirtilmiştir.

Tablo 2: Katılımcıların Demografik Değişkenlere Göre Dağılımı

\begin{tabular}{lcclcc}
\hline Genel Bilgiler & $\boldsymbol{S}$ & $\boldsymbol{\%}$ & Genel Bilgiler & $\boldsymbol{S}$ & $\boldsymbol{\%}$ \\
\hline Yaş & & & Eğitim Durumu & & \\
& & & İlköğretim & 5 & 15.6 \\
20 yaş alt1 & 7 & 19.2 & Ortaögretim & 1 & 30.1 \\
21-30 aras1 & 1 & 30.9 & Ön Lisans & 1 & 47.7 \\
31-40 aras1 & 1 & 38.1 & Lisans & 2 & 5.8 \\
41 ve üstü & 4 & 11.8 & Lisans üstü & 3 & 0.8 \\
Toplam & 3 & 100 & Toplam & 3 & 100 \\
& 65 & & & 65 & \\
\hline
\end{tabular}

Cinsiyet

Çalışma Süresi 
T.Büyükbeșe - E. Sarsıcı - B. Erșahan

Calıșanların Öz Liderlik...

\begin{tabular}{|c|c|c|c|c|c|}
\hline Kadın & 1 & 45.5 & $1-5 \mathrm{y} 11$ & 2 & 71.5 \\
\hline \multirow[t]{4}{*}{ Erkek } & 1 & 54.5 & $6-10 \mathrm{y} 11$ & 4 & 11.2 \\
\hline & & & $11-15$ y1l & 4 & 12.1 \\
\hline & & & $16-20 \mathrm{y} 1 \mathrm{l}$ & 3 & 0.8 \\
\hline & & & 21 ve üstü & 1 & 4.4 \\
\hline Toplam & 3 & 100 & Toplam & 3 & 100 \\
\hline Medeni Durum & & & $\begin{array}{ll}\text { Firma } & \text { Personel }\end{array}$ & & \\
\hline Bekar & 1 & 47,1 & $10-49$ & 1 & 36.7 \\
\hline \multirow[t]{5}{*}{ Evli } & 1 & 52,9 & $50-99$ & 1 & 28.5 \\
\hline & & & $100-149$ & 3 & 9.0 \\
\hline & & & $150-249$ & 4 & 13.2 \\
\hline & & & $250-499$ & 3 & 9.0 \\
\hline & & & 500 ve üstü & 1 & 3.6 \\
\hline Toplam & 3 & 100 & Toplam & 3 & 100 \\
\hline
\end{tabular}

\subsection{Araştırmanın Güvenirliği}

Ölçeklerin güvenirliğinin test edilmesinde kullanılan Cronbach's Alfa değerleri Tablo 1'de yer almaktadır. Cronbach Alfa değerleri Tablo 1'de görüldüğü gibi 0,66 ile 0,96 arasındadır. Güvenirlikleri test edilen 5 değișkenden "Öz Liderlik (Yapıcı Düşünce Stratejisi)" ve "Öz Liderlik (Davranış Odaklı Strateji)" değişkenlerinin 0,8 ve üzeri değer ile en yüksek güvenilirlik oranına sahip olduğu görülmektedir.

Tablo 3: Güvenilirlik Tablosu

\begin{tabular}{|c|c|c|}
\hline Değişkenler & $\begin{array}{l}\text { Soru } \\
\text { Adedi }\end{array}$ & $\begin{array}{r}\text { Cronbach } \\
\text { Alpha Değeri }\end{array}$ \\
\hline $\begin{array}{c}\text { Öz Liderlik (Davranış } \text { Odaklı } \\
\text { Strateji) }\end{array}$ & 16 & .858 \\
\hline Öz Liderlik (Doğal Ödül Stratejisi) & 4 & .667 \\
\hline $\begin{array}{c}\text { Öz Liderlik (Yapıc1 Düşünce } \\
\text { Stratejisi) }\end{array}$ & 7 & .961 \\
\hline Gelişim Kültürü & 8 & .848 \\
\hline Yenilikçi Davranış & 6 & .849 \\
\hline
\end{tabular}




\subsection{Korelasyon Analizi}

Çalışmada öz liderlik (davranış odaklı strateji), öz liderlik (doğal ödül stratejisi), öz liderlik (yapıcı düşünce stratejisi), gelişim kültürü, yenilikçi davranış değişkenleri aralarında anlamlı ilişki olup olmadığını ve ilişkinin yönünü araştırmak için korelasyon testinden faydalanılmıştır.

Korelasyon analizinde katsayı 1'e yaklaştıkça iki değişken arasındaki ilişkinin gücü artmakta ve 0,3 ile 0,5 arasındaki korelasyon orta kuvvette bir korelasyon ilişkisini göstermektedir (İslamoğlu ve Alnıaçık, 2014: 347). Bu katsayılara göre öz liderlik (doğal ödül stratejisi) ile öz liderlik (yapıcı düşünce stratejisi), gelişim kültürü ile öz liderlik (yapıcı düşünce stratejisi) ve yenilikçi davranış ile öz liderlik (yapıcı düşünce stratejisi) arasında orta kuvvette bir korelasyon ilişkisi olduğu görülmektedir.

Korelasyon tablosu incelendiğinde öz liderlik (davranış odaklı strateji) ile öz liderlik (doğal ödül stratejisi) ve öz liderlik (yapıcı düşünce stratejisi) arasında anlamlı ilişki bulunmayıp, diğer bütün araştırma değişkenleri arasında $p \leq 0,01$ ve $\mathrm{p} \leq 0,05$ düzeyinde anlamlı ilişki olduğu ortaya çıkmıştır.

En güçlü ilişki gelişim kültürü ile yenilikçi davranış arasında (.592) ortaya çıkmıştır. Öz liderlik stratejilerinden yapıcı düşünce stratejisi ile, gelişim kültürü (.447) ve yenilikçi davranış (.503) arasında diğer stratejilerden daha yüksek düzeyde ilişki olduğu görülmektedir.

Anlamlı ilişki içerisinde olan değişkenler arasından, öz liderlik (davranış odaklı strateji), gelişim kültürü ve yenilikçi davranış ile pozitif, öz liderlik (doğal ödül stratejisi), öz liderlik (yapıcı düşünce stratejisi) gelişim kültürü ve yenilikçi davranış ile pozitif, öz liderlik (yapıcı düşünce stratejisi), gelişim kültürü ve yenilikçi davranış ile pozitif ve gelişim kültürü yenilikçi davranış ile pozitif yönde ilişki içerisindedir.

Öz liderlik strateji boyutları (davranış odaklı, doğal ödül, yapıcı düşünce), yenilikçi davranış ve gelişim kültürü arasındaki ilişkiler aşağıda verilen Tablo 4 'te gösterilmiştir.

Tablo 4: Araştırma Değişkenlerine Yönelik Korelasyon Analizi

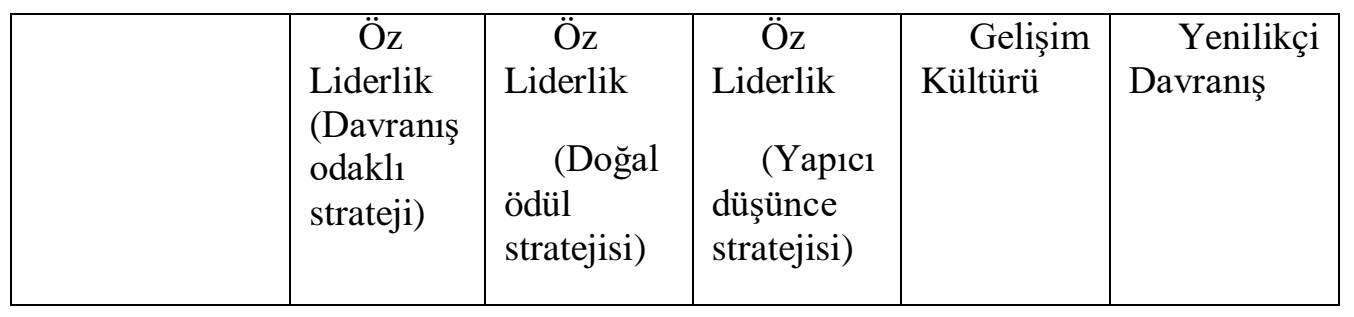


T.Büyükbeșe - E. Sarsıcı - B. Erșahan

Calıșanların Öz Liderlik...

\begin{tabular}{|c|c|c|c|c|c|}
\hline $\begin{array}{l}\text { Öz Liderlik } \\
\text { (Davranış } \\
\text { odaklı strateji) }\end{array}$ & 1 & & & & \\
\hline $\begin{array}{l}\text { Öz Liderlik } \\
\text { (Doğal ödül } \\
\text { stratejisi) }\end{array}$ & .077 & 1 & & & \\
\hline $\begin{array}{l}\text { Öz Liderlik } \\
\text { (Yapıcı } \\
\text { düşünce } \\
\text { stratejisi) }\end{array}$ & .102 & $.386^{* *}$ & 1 & & \\
\hline $\begin{array}{c}\text { Gelişim } \\
\text { Kültürü }\end{array}$ & $.136^{* *}$ & $.213^{* *}$ & $.447 * *$ & 1 & \\
\hline $\begin{array}{c}\text { Yenilikçi } \\
\text { Davranış }\end{array}$ & $.105^{*}$ & $.142^{* *}$ & $.503 * *$ & $.592 * *$ & 1 \\
\hline
\end{tabular}

Not: ${ }^{*} \mathbf{p} \leq 0.05 ; * * p \leq 0.01$

\subsection{Aracılık Etkisi}

Öz liderlik stratejisi ve yenilikçi davranış ilişkisinde gelişim kültürünün aracı rolünün belirlenmesinde Baron ve Kenny (1986) tarafindan önerilen arac1 değişken analizi yöntemi kullanılmıştır.

Buna göre bağımlı değişken (yenilikçi davranış) üzerinde bağımsız (öz liderlik stratejisi) ve aracı değişkenin (gelişim kültürü) ayrı ayrı direkt etkisi olmalı (b ve c), ayrıca bağımsız değişken (öz liderlik stratejisi) ile aracı değişken arasında ilişki olmalıdır (a). 


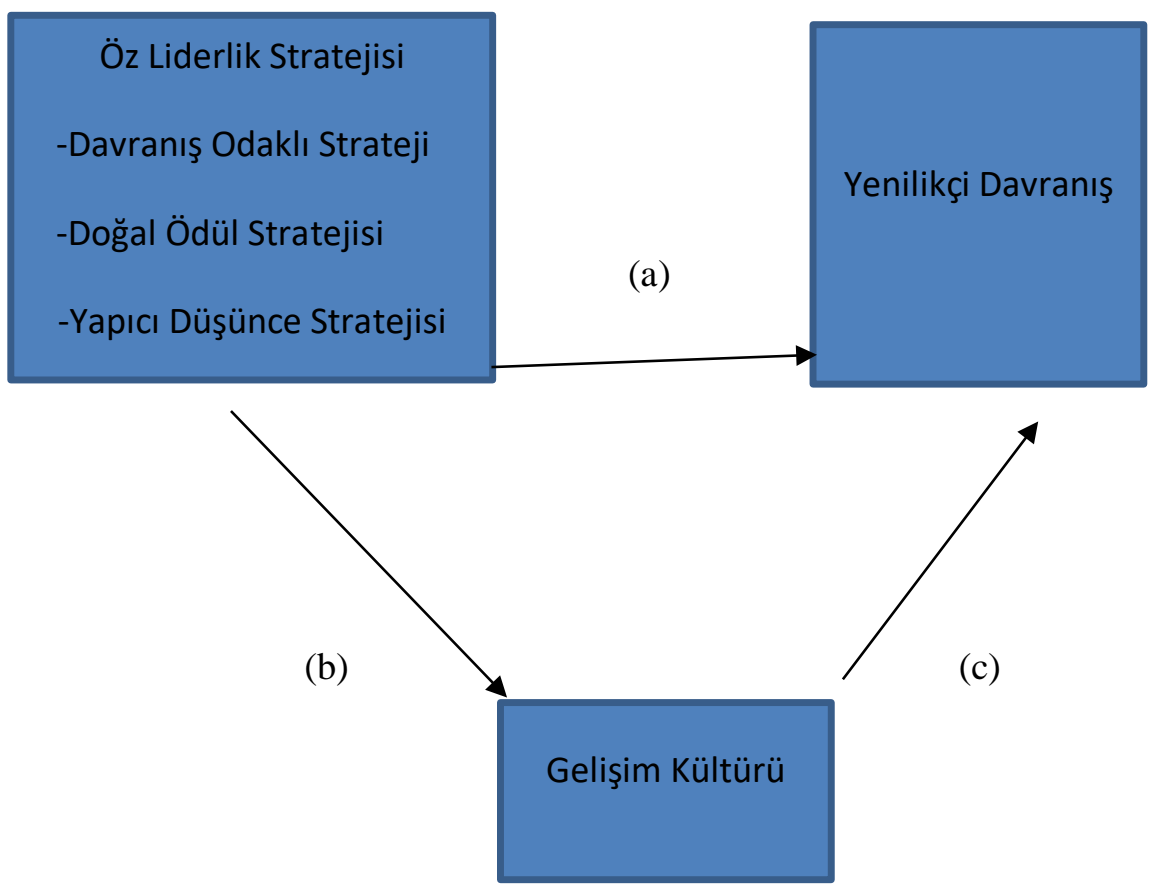

Şekil 2. Baron ve Kenny (1986)'nin Aracı Değişken Modeli

\subsection{Geçerlilik Analizleri}

Öz liderlik stratejisi, yenilikçi davranış ve gelişim kültürü değişkenleri ile tam olarak ölçülemeyen gizli (latent) değişkenler arasındaki ilişkileri incelemek için yapısal eşitlik modeli kullanılmıştır. İlk olarak jenerik (ölçme modeli) model oluşturulmuş ve test edilmiştir. Verilerin istatistiksel analizinde gizli değişkenlerin her biri için DFA (Doğrulayıcı Faktör Analizi) uygulanarak parametrelerin uygunluğu test edilmiştir. Yapısal eşitlik modeli aracı etkiyi test etmek için de kullanılmıştır.

Kullanılan ölçeklerin geçerliliğini test etmek üzere, AMOS 24.0 programı ile doğrulayıcı faktör analizi yapılmıştır. Bu çerçevede öz liderlik stratejisi için üç faktörlü, gelişim kültürü için tek faktörlü, yenilikçi davranış için ise tek faktörlü model test edilmiştir.

Doğrulayıcı faktör analizi bulguları, öz liderlik stratejisi (üç boyutlu), yenilikçi davranış (tek boyutlu) ve gelişim kültürü (tek boyutlu) için şu şekildedir. $\left[\chi^{2} / \mathrm{sd}=1,86 ; \mathrm{p}<.01\right.$; GFI (goodness of fit index)=,84; CFI (comparative fit index)=,91; IFI (incremental fit index)=,91; RMSEA (root mean square error of approximation) $=, 05$ ] modelin iyi uyum verdiği ortaya çıkmıştır. 
Elde edilen model ile verilerin uyumluluğu, çeşitli uyum indekslerine (fit indices) göre değerlendirilmiştir. Tablo 1'de model uyumunun değerlendirilebilmesi için literatürde kabul görmüş uyum iyiliği istatistiklerinin değer aralıkları verilmektedir (Byrne, 2001; Şimşek, 2007).

Tablo 5. Yapısal Eşitlik Modelleri Uyum İndeksleri

\begin{tabular}{|l|l|l|}
\hline Uyum Testi & İyi Uyum & Yeterli Uyum \\
\hline $\mathrm{X} 2 / \mathrm{df}$ & $0 \leq \chi^{2 / \mathrm{d} f \leq 2}$ & $2 \leq \chi^{2 / \mathrm{df} \leq 3}$ \\
\hline CFI & $0,95 \leq \mathrm{CFI} \leq 1,00$ & $0,90 \leq \mathrm{CFI} \leq 0,95$ \\
\hline RMSEA & $0 \leq \mathrm{RMSEA} \leq 0,05$ & $0,08 \leq \mathrm{RMSEA} \leq 0,05$ \\
\hline TLI & $0,95 \leq \mathrm{TLI} \leq 1,00$ & $0,90 \leq \mathrm{TLI} \leq 0,95$ \\
\hline
\end{tabular}

$\chi^{2}=$ Chi-Square (Ki-Kare); df=Degree of Freedom (Serbestlik Derecesi); GFI=Goodness-of fit index (İyilik Uyum İndeksi); AGFI=Adjusted goodness-offit index(Düzeltilmiş İyilik Uyum İndeksi), CFI=Comparative fit index (Karşılaştırmalı Uyum İndeksi); RMSEA=The root mean square error (Yaklaşı1k Hataların Ortalama Karekökü); NFI=Normed fit index (Normlaştırılmış Uyum İndeksi); TLI=Tucker Lewis index (Tucker Lewis İndeksi).

Model uyum iyilik uyum indeksine bakıldığında CFI değerlerinin 0.90' dan büyük olduğu ve RMSEA değerinin 0.08 ' den küçük olduğu modelin kabul edilebilir düzeyde olduğunu göstermektedir (Kline, 2011). Yine $\chi^{2} / \mathrm{sd}$ değeri istenen değer olan 4' ün altında olduğu görülmektedir.

Bu verilerden yola çıkarak, araştırma amacına ulaşmak için kurulan, özliderlik stratejisinin yenilikçi davranışı olumlu ve istatistiksel olarak anlamlı bir şekilde etkileyeceği, gelişim kültürünün de bu etkide aracı rol oynayacağı modelinin doğrulanmış olduğu ifade edilebilir.

\subsection{Yapısal Eşitlik Modellemesi ile Aracılık Testi}

Aşağıda Şekil 3’te öz liderlik stratejisinin yenilikçi davranışa etkisinde gelişim kültürünün aracı rolüne yönelik ortaya konulan yapısal eşitlik modeli görülmektedir. Gizli değişkenlere ait DFA yapıldıktan sonra, Şekil 3 'te gösterilen final modeli şeklinde adlandırılabilecek yapısal eşitlik modeli oluşturulmuştur. Nihai modelin uyum kriterleri sinanarak verinin modele uygunluğu R1 ve R2 hata payıyla araştırılmış, ardından gizli değişkenler arasında var olduğu düşünülen ilişkiler hipotezlerle sınanmıştır. 
Öz liderlik stratejisinin yenilikçi davranışa etkisinde gelişim kültürünün aracılık rolü olup olmadığı iki ayrı yol analizi ile araştırılmıştır. Kurulan yapısal yol analizi modelleri AMOS 24.0 yazılımı kullanılarak test edilmiştir. Meydan ve Şeşen (2011)'in belirttiği üzere, aracılık testlerinde yapısal eşitlik modeli kullanılması doğrusal regresyon analizine göre daha güvenilir sonuçlar ortaya çıkarmaktadır. Bundan dolayı, bu araştırmada da iki ayrı yol analizi modeli oluşturulmuştur. 


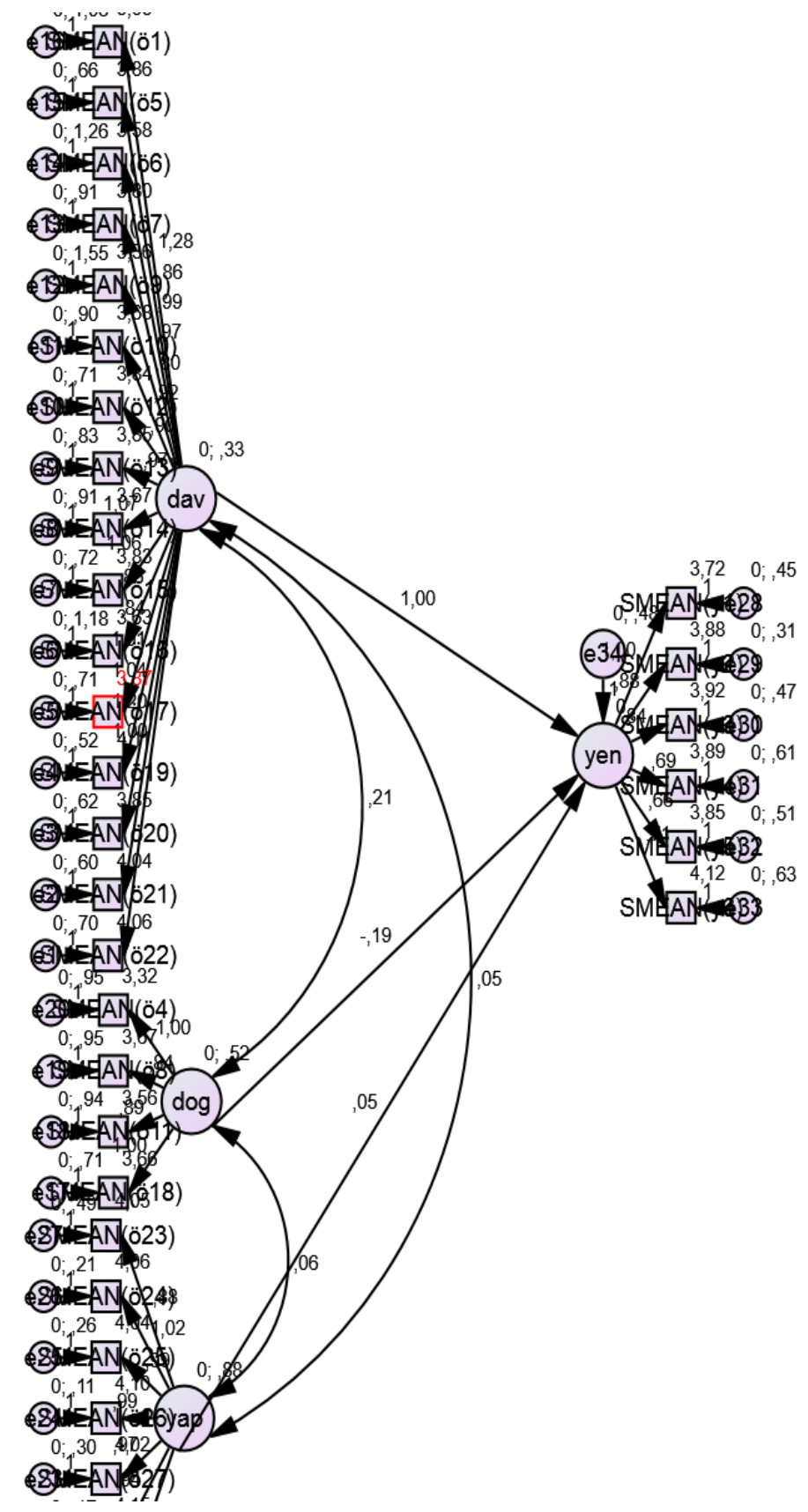

Şekil 3: Yapısal Eşitlik Modellemesi 
Aracılık etkisini değerlendirmek üzere model testleri sonucunda elde edilen regresyon katsayıları Şekil-3'te verilmiştir. Buna göre birinci modelde, öz liderlik strateji boyutunun yenilikçi davranış üzerindeki etkisi test edilmiştir. Elde edilen regresyon katsayıları her bir yol için parantez içerisinde verilmiştir. Birinci model incelendiğinde davranış odaklı strateji boyutunun yenilikçi davranış üzerinde anlamlı etkisinin (H1.1 KABUL) olduğu (standardize beta=1.00; $p>.01$ ); doğal ödül stratejisi boyutunun yenilikçi davranış üzerinde anlamlı etkisinin (H1.2 KABUL) olduğu (standardize beta $=.-19 ; \mathrm{p}<.001$ ); yapıcı düşünce stratejisi boyutunun yenilikçi davranış üzerinde anlamlı etkisinin (H1.3 KABUL) olduğu (standardize beta=,05; $\mathrm{p}<.01$ )görülmektedir. Birinci model kabul edilebilir uyum değerleri verilmiştir $\left[\chi^{2} / \mathrm{sd}=2.08 ; \mathrm{p}<.01 ; \mathrm{CFI}=.91 ; \mathrm{IFI}=.91 ; \mathrm{RMSEA}=.05\right]$. $\mathrm{Bu}$ durumda, Baron ve Kenny (1986) yöntemi takip edildiğinde, bir sonraki modelde davranış odaklı strateji, doğal ödül stratejisi ve yapıcı düşünce stratejisinin yenilikçi davranış ile ilişkisi dikkate alınacaktır. 


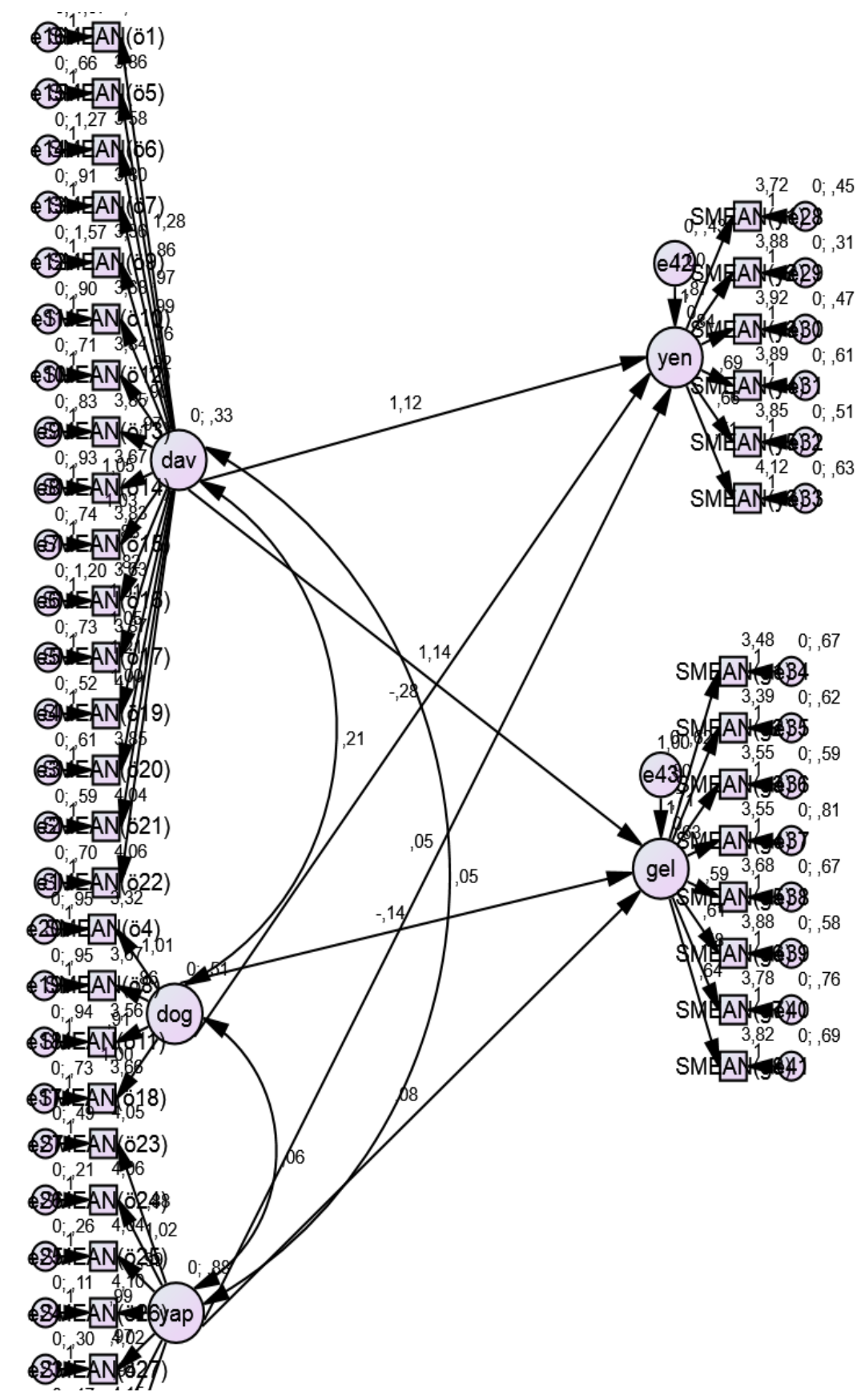

Şekil 4: Yapısal Eşitlik Modellemesi İle Aracılık Testleri 
İkinci modelde gelişim kültürü aracı değişken olarak modele dahil edilmiştir. Model incelendiğinde her üç öz liderlik boyutunun gelişim kültürü üzerinde anlamlı etkisi olduğu görülmektedir (H2.1, H2.2. ve H2.3 KABUL) ve davranış odaklı strateji boyutunun gelişim kültürü üzerindeki etkisi diğerlerinden daha yüksek düzeydedir. Ayrıca gelişim kültürünün yenilikçi davranış üzerinde de anlamlı etkisinin olduğu anlaşılmaktadır (H3 KABUL). Bu durumda Baron ve Kenny'nin 2 ve 3'üncü şartları da sağlanmış olmaktadır. Gelişim kültürü modele dahil edildiğinde ise, hem davranış odaklı (standardize beta $=1,12 ; p>.05$ ), hem doğal ödül (standardize beta $=1,14 ; \mathrm{p}>.05$ ) hem de yapıcı düşünce stratejilerinin (standardize beta=-,14; $\mathrm{p}>.05$ ) yenilikçi davranış üzerindeki etkileri anlamsızlaşmaktadır. Dolayısıyla, Baron ve Kenny'nin 4'üncü şartı da gerçekleşmiştir. Bu nedenle davranış odaklı strateji, doğal ödül stratejisi ve yapıcı düşünce stratejisinin yenilikçi davranış üzerindeki etkilerinde gelişim kültürü Tam arac1 rol oynamaktadır (H4.1, H4.2 ve H4.3 RED). İkinci modelin indeks değerleri kabul edilebilir sınırlar içerisindedir $\left[\chi^{2} / \mathrm{sd}=1,96 ; \mathrm{p}<.01 ; \mathrm{CFI}=.88\right.$; IFI=.90; RMSEA=.05].

\section{SONUÇ ve ÖNERILER}

$\mathrm{Bu}$ araştırma, Adıyaman organize sanayii bölgesindeki özel sektör çalışanlarının öz liderlik stratejisi, yenilikçi davranış ve gelişim kültürünün düzeyini ve birbirleri ile olan ilişkileri inceleyerek gelişim kültürünün bu ilişkideki aracı rolünü analiz etmeyi amaçlamıştır.

Değişkenler arasında olabilecek ilişkileri belirlemek amacıyla korelasyon analizi yapılmış ve bu analiz ile şu sonuçlara ulaşılmıştır: Gelişim kültürü ile öz liderlik ve yenilikçi davranış ile öz liderlik arasında orta kuvvette bir korelasyon ilişkisi olduğu görülmüştür. Anlamlı ilişki içerisinde olan değişkenler arasından, öz liderlik (davranış odaklı strateji) davranışı; gelişsim kültürü ve yenilikçi davranış ile pozitif ilişki içerisindedir. Öz liderlik (doğal ödül stratejisi) davranışı, öz liderlik (yapıcı düşünce stratejisi), gelişim kültürü ve yenilikçi davranış ile pozitif ilişki içerisindedir. Öz liderlik (yapıcı düşünce stratejisi), gelişim kültürü ve yenilikçi davranış ile pozitif ve gelişim kültürü yenilikçi davranış ile pozitif yönde iliş̧i içerisindedir. Elde edilen bu bulgular benzer araştırmalar ile de uyum sağlamaktadır ( Lau ve Ngo 2004, Akkoç vd. 2011, Weia vd. 2011).

Öz liderlik becerilerinin yenilikçi davranış ile pozitif yönde bir ilişkisini olduğu belirlenmiştir. Elde edilen bu bulgular benzer araştırmalar ile de uyum sağlamaktadır (West vd. 2003, Howell ve Avolio 1993, Elenkov ve Manev 2009).

Aracılık etkisini değerlendirmek üzere yukarıda izah edilen Baron ve Kenny (1986)'nin yöntemi esas alınmıştır. Birinci model kabul edilebilir uyum değerleri vermiştir. Bir sonraki modelde davranış odaklı strateji, doğal ödül stratejisi ve yapıcı düşünce stratejisinin yenilikçi davranış ile ilişkisi dikkate alınmıştır. 
İkinci modelde gelişim kültürü aracı değişken olarak modele dahil edilmiştir. Model incelendiğinde her üç öz liderlik boyutunun gelişim kültürü üzerinde anlamlı etkisi olduğu görülmektedir (H2.1, H2.2. ve H2.3 KABUL) ve davranış odaklı strateji boyutunun gelişim kültürü üzerindeki etkisi diğerlerinden daha yüksek düzeydedir. Ayrıca gelişim kültürünün yenilikçi davranış üzerinde de anlamlı etkisinin olduğu anlaşılmaktadır (H3 KABUL). Bu durumda Baron ve Kenny'nin 2 ve 3 'üncü şartları da sağlanmış olmaktadır.

Gelişim kültürü modele dahil edildiğinde ise, hem davranış odaklı, hem doğal ödül, hem de yapıcı düşünce stratejilerinin, yenilikçi davranış üzerindeki etkileri anlamsızlaşmaktadır. Dolayısıyla, Baron ve Kenny'nin 4'üncü şartı da gerçekleşmiştir. Bu nedenle davranış odaklı strateji, doğal ödül stratejisi ve yapıcı düşünce stratejisinin yenilikçi davranış üzerindeki etkilerinde gelişim kültürü Tam aracı rol oynamaktadır (H4.1, H4.2 ve H4.3 RED). İkinci modelin indeks değerleri kabul edilebilir sınırlar içerisindedir

Yapılan bu araştırmada bazı sınırlılıklar bulunmaktadır. Araştırmanın sadece Adıyaman'daki organize sanayii bölgesinde faaliyet gösteren işletmelerde yapılması, araştırmanın önemli bir kısıtı olarak karşımıza çıkmaktadır. Bu nedenle araştırmanın değişik bölgelerde ve sektörlerde yapılması farklı sonuçlara ulaşılmasını mümkün kılabilir.

Akademisyenler tarafindan yapılacak başka bir çalışmada öz liderlik becerilerinin arttırılmasında girişimci davranışlarının yenilikçi davranış üzerindeki etkileri araştırmaları önerilebilir.

Elde edilen bu değerlendirmeler sonucunda bazı önerilerde bulunulabilir. Bunlar;

- Özel işletmelerde çalışanların öz liderlik ve yenilikçilik davranışlarının daha etkin olabilmesi için gerekli olan gelişim odaklı kültürel ve yapısal faktörlerin belirlenmesine yönelik çalışmalar yapılmalı,

- Öz liderlik konusunda önemli aşamalar kaydetmiş üretim sektöründe hizmet veren işletmelerin örgüt kültürleri ve yenilikçilik davranışları detaylı analiz edilmeli,

- Örgütsel gelişimi ve yenilikçiliği etkileyen faktörler ayrı bir araştırma konusu olarak ele alınmalı

- Müşteri talep ve ihtiyaçları incelenerek kurum ve müşteriye değer katacak faaliyetlere odaklanılması, 
- Yönetim yapısının öz liderlik ve yenilikçilik konusunda oluşabilecek hatalara karşı anlayışılı olmasının sağlanması,

- Çalışanların öğrenme kapasitelerinin arttırılmasının sağlanması,

- Bireylerin yenilikçi ve gelişimci olabilmelerini sağlamak için şeffaf bir ödül sisteminin sağlanması çalışmalarının yapılması başarıya giden yolda katkı sağlayacaktır.

Söz konusu çalışmanın farklı bölge ve sektörlerde de yapılması konunun daha iyi anlaşılmasına katkı sağlayacaktır. Sonuç olarak; çalışanların öz liderlik davranışlarının hem gelişim kültürün hem de yenilikçilik davranışına etki ettiği ve bu öz liderlik stratejilerinin gelişim kültürü aracılığıyla çalışanların yenilikçi davranışında artışa neden olduğu ortaya konulmuştur. Günümüz işletmelerinde rekabet üstünlüğünün sürdürülebilir olması için çalışanların öz liderlik becerilerinin geliştirilmesine olanak sağlayacak bir kültür geliştirmeleri, bu sayede arzulanana yenilikçi davranışı artırabilecekleri önerilebilir.

\section{KAYNAKÇA}

Akkoç, İrfan; Turunç, Ömer ve Çalışkan, Abdullah (2011), "Gelişim Külttürü ve Lider Desteğinin Yenilikçi Davranış ve İş Performansına Etkisi: İşAile Çatışmasının Aracılık Rolü”, İş. Güç Endüstri İlişkileri ve İnsan Kaynakları Dergisi, 13 (4), ss. 83-114

Akkoç, İrfan (2012), “Gelişim Kültürü ve Etik İklimin Yenilikçiliğe Etkisinde Dağıtım adaletinin Rolü”, Uluslararası Alanya İşletme Fakültesi Dergisi, C:4, S:3, ss. 45-60.

Akkoç, İrfan, Çalışkan Abdullah ve Turunç Ömer (2012), “Gelişim Rasyonel Alt Kültürlerinin Girişimci Davranışa Etkisi: Algılanan Çevresel Belirsizliğin Aracılık Rolü”, Anadolu Üniversitesi Sosyal Bilimler Dergisi, 12(4), ss. 65-83.

Alegre, Joaquin; Chiva, Ricardo (2008), “Assessing The Impact of Organizational Learning Capability on Product Innovation Performance: An Empirical Test”, Technovation, Cilt: 28, ss. 315

Anderson Joseph ve Prussia, Gregory (1997), “The Self-Leadership Questionnaire: Preliminary Assessment of Construct Validity”. The Journal of Leadership Studies 4(2), ss. 119-143. 
Ay, Gamze (2017), "Yönetici Ve Yönetici Asistanlarının Öz Liderlik Düzeylerinin Belirlenmesine Yönelik Bir Araştırma”, Uluslararası Sosyal Araştırmalar Dergisi, Cilt: 10 Sayı: 52, ss. 1-12

Basım, Hamdullah. N., Korkmazyürek, Haluk ve Tokat, Ali Osman (2008), “Çalışanların Öz Yeterlilik Algılamasının Yenilikçi ve Risk Alma Üzerine Etkisi: Kamu Sektöründe Bir Uygulama”, Sosyal Bilimler Dergisi, 19, ss. 121-130

Baron, Reuben ve Kenny, David (1986), “The Moderator- Mediator Variable Distinction In Social Psychological Research: Conceptual, Strategic and Statistical Considerations". Journal of Personality and Social Psychology, 51(6), ss. 1173-1182.

Bunch, Kay J. (2007), “Training Failure as A Consequence of Organizational Culture”, Human Resource Development Review, 6:2, ss. 142-163.

Burns David (1980), Feeling good: The New Mood Therapy. William Morrow, New York

Burns, Tom Ve Stalker, Gorge (1961), The Management Of Innovation, Tavistock Publications, London.

Byrne, Barbara M. (2001), Structural Equation Modeling with AMOS: Basic Concepts, Applications, And ProgrammingLondon: LEA.

Carson, Jay B., Paul, Tesluk E. ve Jennifer A. Marrone (2007), “Shared Leadership in Teams: An Investigation of Antecedent Conditions and Performance”. Academy of Management Review 50(5), ss. 1217-1234.

Denıson, Daniel R. Ve Mishra, Aneil K. (1995), “Toward A Theory Of Organizational Culture And Effectiveness”, Organization Science, 6:2, ss. 204-223.

Garson, G. David (2009). Structural Equation Modeling, Erişim 26 Mart 2017, http://faculty.chass.ncsu.edu/garson/PA765/structur.htm.

Göksoy, Süleyman; Emen, Engin ve Yenipınar, Şenyurt (2014), “Öğretmenlerin Öz Liderlik Rolleri İle Örgütsel Vatandaşık Davranışları Arasındaki İlişkinin İncelenmesi”, “KSÜ Sosyal Bilimler Dergisi, Nisan 2014, Cilt:11, Say1:1, ss.103-116.

Hair, Joseph F., Jr., Anderson, Rolph E. ve Black, William C. (1998), Multivariate Data Analysis, (5th Edition). Upper Saddle River, NJ: PrenticeHall. 
Heimerdinger, Sarah R. ve Verlin B. Hinsz (2008), "Failure Avoidance Motivation in a Goal-Setting Situation”. Human Performance 21: ss. 383-395.

Hinsz, Verlin B. ve David C. Matz (1997), “Self-Evaluations Involved in Goal Setting and Task Performance”. Social Behavior and Personality 25(2), ss.177-182.

Houghton Jeffery D. ve Yoho Steven K. (2005), “Toward a Contingency Model of Leadership and a Psychological Empowerment: When Should SelfLeadership Be Encouraged?”, Journal of Ledareship and Organizational Studies 11(4): 65-83

Houghton Jeffery D. ve Neck Cristopher P. (2002), “The Revised SelfLeadership Questionnaire: Testing a Hierarchical Factor Structure for Self-Leadership”, Journal of Managerial Psychology 17(8), ss. 672692.

İslamoğlu, Ahmet H. ve Alnıaçık, Ümit (2014), Sosyal Bilimlerde Araştırma Yöntemleri, Seçkin Yayıncılık, 4. Baskı, Ankara.

Kayral, İbrahim H. (2015), “Öz Liderlik Becerilerinin, Sağlık Çalışanlarının İş Tatminleri ve İş Performanslarına Etkisi”, Hacettepe Sağlık İdaresi Dergisi, 18(2), ss. 143-159

Keeny, Breda; Reedy, Eileen (2007), "The Impact of Organisational Culture Factors on Innovation Levels in SMEs: An Empirical Investigation”, The Irish Journal of Management, Ocak:119.

Kline, Rex. B. (2011), Principles and Practice of Structural Equation Modeling. Guilford Press.

Locke, Edwin A. ve Garry P. Latham (1990). A Theory of Goal Setting and Task Performance. Englewood Cliffs, NJ: Prentice-Hall.

Lok, Peter, Westwood, Robert ve Crawford, John (2005), “Perceptions of Organizational Subculture and Their Significance for Organizational Commitment”, Applied Psychology, 54(4), ss. 490-514.

Manz, Charles C. (1986), "Self-Leadership: Toward An Expanded Theory of Self- Influence Processes in Organizations”. Academy of Management Review11(3), ss. 585-600.

Meydan, Cem H. ve Şeşen, Harun (2011), Yapısal Eşitlik Modellemesi AMOS Uygulamaları, Ankara, Detay. 
Neck, Christopher P. ve Jeffery D. Houghton (2006), “Two Decades of SelfLeadership Theory and Search: Past Developments, Present Trends, and Future Possibilities”. Journal of Managerial Psychology 21(4): 270295.

Ostroff, Cheri ve Schmitt, Neal (1993), “Configurations of Organizational Effectiveness and Efficiency”, Academy of Management Journal, 36, ss. 1345-1361.

Perry, Monica L., Craig Pearce, ve Henry P. Sims (1999), “Empowered Selling Teams: How Shared Leadership Can Contribute to Selling Team Outcomes”. Journal of Personel Selling and Sales Management 19(3), ss. 35-51.

Pervaiz, Ahmed (1998), “Culture and Climate for Innovation”, European Journal of Innovation Management, 1:1, ss. 30-31.

Quinn, Robert E. (1988), Beyond Rational Management: Mastering The Paradoxesn And Competing Demands Of High Performance, San Francisco: Jossey-Bass.

Scott, Tim, Mannıon, Russel, Marshall, Martin Ve Davies, Huw (2003), “Does Organizational Culture Influence Healthcare Performance? A Review of The Evidence”, Journal of Health Services Research and Policy, 8(2), ss. $105-117$.

Scott, Susanne ve Reginald, Bruce (1994), "Determinants of innovative behavior: a path model of individual innovation in the workplace", Academy of Management Journal, Vol. 37, No. 3, ss. 580-607.

Sekaran, Uma (1992), Research Methods For Business, Canada: John Wiley ve Sons, Inc.

Shih, Hsi-An ve Ely Susanto (2011), "Is innovative behavior really good for the firm? Innovative work behavior, conflict with coworkers and turnover intention: moderating roles of perceived distributive fairness”, International Journal of Conflict Management, Vol. 22 No. 2, pp. 111-130.

Stewart, Greg L., Stephan, Courtright ve Charles C. Manz (2011), "SelfLeadership: A Multilevel Review”. Journal of Management 37(1), ss. 185-222. 
Sorescu, Alina, Chandy, Rajesh K. ve Prabhu, Jaideep C. (2003), Sources and Financial Consequences of Radical Innovation: Insights from Pharmaceuticals, Journal of Marketing, 67, ss. 82-102.

Şimşek, Ömer F. (2007), Yapısal Eşitlik Modellemesine Giriş. Ankara: Ekinoks Yayınları.

Tabak, Akif; Sığrı, Ünsal ve Türköz, Tolga (2013), “Öz Liderlik Ölçeğinin Türkçeye Uyarlanması Çalışması”, bilig, Sayı:67, ss. 213-246.

Turgut, Ercan ve Begenirbaş, Memduh (2014), “İlişkisel Sosyal Sermayenin Yenilikçi Davranışa Etkisinde Örtülü Bilgi Paylaşımı Davranışının Aracılık Rolü”, Niğde Üniversitesi İIBBF Dergisi, Cilt: 7, Sayı: 1, ss. 146160.

Wang, Sheng; Guidice, Rebecca M.; Tansky, Judich W.; Wang Zhong-Ming. (2010). "When R\&D Spendings is Not Enough: The Critical Role of Culture When You Really Want to Innovate", Human Resource Management, Cilt: 49, Sayı: 4, 767

West, Michael A. ve Farr, James L. (1989), Innovation at Work: Psychological Perspectives, Social Behavior, 4, ss. 15-30.

Yuan, Fierong ve Richard, W. Woodman (2010). "Innovative Behavior in The Workplace: The Role of Performance and Image Outcome Expectations”, Academy of Management Journal, 53, 2, ss. 323-342. 